\title{
Root length density distribution and associated soil water dynamics for tomato plants under furrow irrigation in a solar greenhouse
}

\author{
QIU Rangjian ${ }^{1,2}$, DU Taisheng ${ }^{2 *}$, KANG Shaozhong ${ }^{2}$ \\ ${ }^{1}$ Collaborative Innovation Center on Forecast and Evaluation of Meteorological Disasters, Jiangsu/Key Laboratory of \\ Agricultural Meteorology, Nanjing University of Information Science and Technology, Nanjíng 210044, China; \\ ${ }^{2}$ Center for Agricultural Water Research in China, China Agricultural University, Beijing 100083, China
}

\begin{abstract}
Furrow irrigation is a traditional widely-used irrigation method in the world. Understanding the dynamics of soil water distribution is essential to developing effective furrow irrigation strategies, especially in water-limited regions. The objectives of this study are to analyze root length density distribution and to explore soil water dynamics by simulating soil water content using a HYDRUS-2D model with consideration of root water uptake for furrow irrigated tomato plants in a solar greenhouse in Northwest China. Soil water contents were also in-situ observed by the $\mathrm{ECH}_{2} \mathrm{O}$ sensors from 4 June to 19 June and from 21 June to 4 July, 2012. Results showed that the root length density of tomato plants was concentrated in the $0-50 \mathrm{~cm}$ soil layers, and radiated $0-18 \mathrm{~cm}$ toward the furrow and $0-30 \mathrm{~cm}$ along the bed axis. Soil water content values simulated by the HYDRUS-2D model agreed well with those observed by the $\mathrm{ECH}_{2} \mathrm{O}$ sensors, with regression coefficient of 0.988 , coefficient of determination of 0.89 , and index of agreement of 0.97 . The HYDRUS-2D model with the calibrated parameters was then applied to explore the optimal irrigation scheduling. Infrequent irrigation with a large amount of water for each irrigation event could result in 10\%-18\% of the irrigation water losses. Thus we recommend high irrigation frequency with a low amount of water for each irrigation event in greenhouses for arid region. The maximum high irrigation amount and the suitable irrigation interval required to avoid plant water stress and drainage water were $34 \mathrm{~mm}$ and 6 days, respectively, for given daily average transpiration rate of $4.0 \mathrm{~mm} / \mathrm{d}$. To sum up, the HYDRUS-2D model with consideration of root water uptake can be used to improve irrigation scheduling for furrow irrigated tomato plants in greenhouses in arid regions.
\end{abstract}

Keywords: root length density distribution; HYDRUS-2D model; soil water content; irrigation scheduling; greenhouse

Citation: QIU Rangjian, DU Taisheng, KANG Shaozhong. 2017. Root length density distribution and associated soil water dynamics for tomato plants under furrow irrigation in a solar greenhouse. Journal of Arid Land, 9(5): 637-650. doi: $10.1007 / \mathrm{s} 40333-017-0064-9$

\section{Introduction}

Greenhouse cultivation is widely used for crop production. It facilitates high water use efficiency, enables the grower to maintain an optimal environment, prolongs the growing season, and produces a high-quality product (Harmanto et al., 2005). Irrigation is the only source of water in a greenhouse, so it is critical to both yield and quality of the crops grown in the greenhouse (Harmanto et al., 2005; Wang et al., 2009). Drip irrigation is a new water-saving technology that could save water and fertilizer and improve both crop yield and quality. Many studies have investigated the scheduling of drip irrigation (e.g., Yuan et al., 2004; Harmanto et al., 2005; Wang

*Corresponding author: DU Taisheng (E-mail: dutaisheng@cau.edu.cn)

Received 2017-02-06; revised 2017-06-06; accepted 2017-07-08

CC Xinjiang Institute of Ecology and Geography, Chinese Academy of Sciences, Science Press and Springer-Verlag GmbH Germany 2017 
et al., 2009). However, furrow irrigation, a traditional technology with low energy use efficiency and little investment, is still the principal irrigation method widely-used in greenhouses, especially in China (Crevoisier et al., 2008; Iqbal et al., 2016). Under furrow irrigation, plants are usually grown on ridges (beds) between two furrows, and irrigation water flows down to the blocked-end furrow. Furrow irrigation may lead to different plant root distributions compared to other irrigation methods, such as drip irrigation and basin irrigation (Ning et al., 2015; He et al., 2016). For example, Zotarelli et al. (2009) reported that root density is higher in deeper soil layers under furrow irrigation while it is higher in shallower soil layers under surface and subsurface drip irrigation. Furthermore, root density under surface drip irrigation is $48 \%-54 \%$ higher than those under both subsurface drip irrigation and furrow irrigation at 45 and 66 days after transplanting (DAT), respectively.

Roots take up water and dissolve nutrients from the soil, thus transferring them to the plant. The root density distribution of a plant's roots could affect root water uptake and in turn influence soil water distribution (Vrugt et al., 2001a). Zhou et al. (2007) pointed out that soil water content is hardly influenced by root water uptake below $60-\mathrm{cm}$ soil depth and does not change below $80-\mathrm{cm}$ soil depth because of low root density below $60-\mathrm{cm}$ soil depth. Clearly, a better understanding of root density and distribution pattern and root water uptake under furrow irrigation will allow for a more accurate simulation of soil water distribution for plants.

Simulating soil water movement by models is essentially helpful to understand the effects of plant-root systems on water transfer from soil to plant (Vrugt et al., 2001b). Due to the geometry of the infiltration area, water transfer under furrow irrigation can be considered to be two-dimensional over a cross section (Crevoisier et al., 2008; Tafteh and Sepaskhah, 2012). A two-dimensional water transfer model is thus suitable for simulating soil water dynamics (Mailhol et al., 2001). The HYDRUS-2D model has been successfully used for simulating water transfer under furrow irrigation (Abbasi et al., 2004; Crevoisier et al., 2008; Ebrahimian et al., 2012; Zhang et al., 2013, 2014). For examples, Abbasi et al. (2004) showed that the estimated soil water content values simulated by the HYDRUS-2D model agreed well with the observed soil water content values in a blocked-end furrow cross section. Crevoisier et al. (2008) pointed out that the HYDRUS-2D model can accurately simulate soil water content under both conventional furrow irrigation and alternative furrow irrigation. An improved understanding of water transfer from soil to plant is essential to efficient irrigation practices (Vrugt et al., 2001a; Zuo et al., 2006).

The purposes of this study are: (1) to analyze root density distribution of tomato plants under furrow irrigation in a solar greenhouse; (2) to explore soil water dynamics by simulating soil water content using a HYDRUS-2D model with consideration of root water uptake under furrow irrigation; and (3) to schedule furrow irrigation using the parameter values calculated by the HYDRUS-2D model.

\section{Materials and methods}

\subsection{Experimental site and plant materials}

The experiment was conducted in 2012 at Shiyanghe Experimental Station for Water-Saving in Agriculture and Ecology, China Agricultural University, in Wuwei City, Gansu Province of Northwest China $\left(37^{\circ} 52^{\prime} \mathrm{N}, 102^{\circ} 51^{\prime} \mathrm{E} ; 1581 \mathrm{~m}\right.$ a.s.l.). The region is characterized by a continental arid climate, with annual average temperature of $8.8^{\circ} \mathrm{C}$, average annual precipitation of $164.4 \mathrm{~mm}$ and average annual pan evaporation of $2000 \mathrm{~mm}$. Solar radiation is abundant with average sunshine of $3000 \mathrm{~h} / \mathrm{a}$. The average frost-free period is $150 \mathrm{~d} / \mathrm{a}$. Groundwater table in this region is below 25-m deep.

The solar greenhouse used in this study was constructed from a steel frame in 2007 , covered with a thermal polyethylene sheet. A roof ventilation system was used to control the interior microclimate. More detailed description of the solar greenhouse can be found in Qiu et al. (2011). The soil in the solar greenhouse is silt loam with average bulk density of $1.46 \mathrm{~g} / \mathrm{cm}^{3}$, average field water capacity of $0.36 \mathrm{~cm}^{3} / \mathrm{cm}^{3}$ and average wilting point of $0.13 \mathrm{~cm}^{3} / \mathrm{cm}^{3}$. Soil texture at depths 
of $0-100 \mathrm{~cm}$ is composed of $12.6 \%$ clay, $64.3 \%$ silt and $23.1 \%$ sand. Irrigation water is from a nearby well with electrical conductivity of $0.52 \mathrm{dS} / \mathrm{m}$.

A common local variety of tomato (Solanum lycopersicum L., cultivar Oyadi) was used in the experiment. The tomato plants were transplanted on 28 February, 2012. Two rows of seedlings with one seedling per hole were evenly transplanted along the edge of each furrow row $(40 \mathrm{~cm}$ between rows and $40 \mathrm{~cm}$ between plants within a row). The widths of the bed and nearby furrow were 75 and $40 \mathrm{~cm}$, respectively (Fig. 1). A more detailed description of the planting pattern can be found in Qiu et al. (2013). Tomato plants were cultivated in a north-south direction. We covered the soil with clear polyethylene film ( $1.2 \mathrm{~m}$ wide and $5 \mu \mathrm{m}$ thick) along each row (furrow plus bed) after transplanting to reduce soil evaporation and to increase soil temperature. We irrigated the tomato plants with $27.9 \mathrm{~mm}$ water during transplanting and also on $12^{\text {th }}$ day after transplanting (DAT) to keep the seedlings alive and to enhance growth of transplanted plants. From 12 DAT, plants were irrigated to $90 \%$ of field water capacity $\left(\theta_{F}\right)$ when the mean soil volumetric water content $\left(\theta_{i}\right)$ in the main root zone $\left(Z_{r}=0.5 \mathrm{~m}\right)$ was depleted to $75 \%( \pm 2 \%)$ of $\theta_{F}$. For each irrigation event, the amount of water irrigated $(D ; \mathrm{mm})$ was calculated as follows:

$$
D=1000 \times\left(0.9 \theta_{F}-\theta_{i}\right) \times Z_{r} \text {. }
$$

Irrigation water was applied to the blocked-end furrow, and the amount of water irrigated for each irrigation event was measured by a water meter.

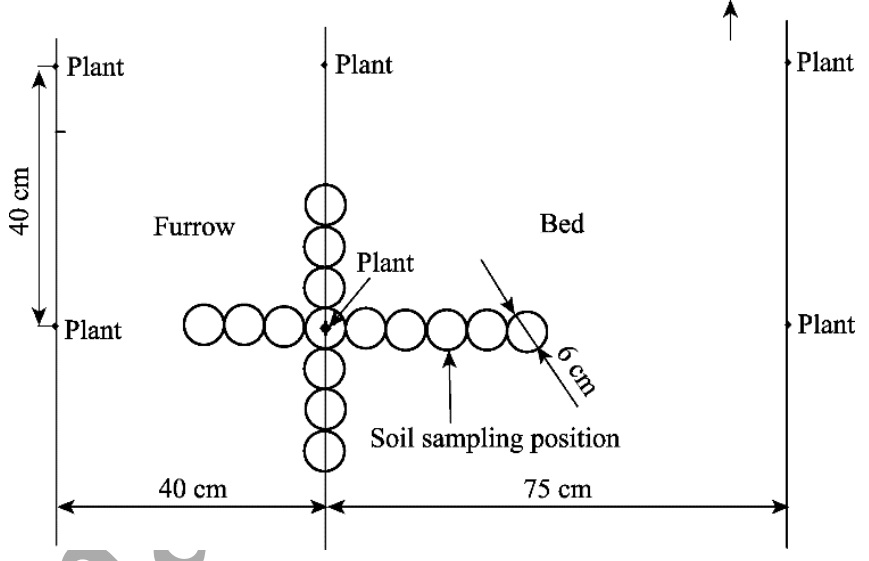

Fig. 1 Schematic diagram of planting pattern and soil core sampling

\subsection{Measurements and methods}

$\mathrm{ECH}_{2} \mathrm{O}$ sensors (Decagon Devices, Pullman, WA, USA) were used to observe soil water content with an accuracy of $\pm 3 \%$ and the data were recorded every 30 min using EM 50 data loggers (Decagon Devices, Pullman, WA, USA). Three sets of $\mathrm{ECH}_{2} \mathrm{O}$ sensors were placed (5 sensors per set), i.e., one set in the center of the furrow, one set at the edge of the furrow, and one set in the center of the bed. The 5 sensors in each set were placed at depths of $0-10,10-20,20-40,40-60$ and $60-80 \mathrm{~cm}$, respectively.

We measured the sap flow of tomato plants by the heat balance method with the Flow 32-1K system (Model SGA 13-WS, Dynamax, Houston, TX, USA). Sap flow of two tomato plants was monitored from 4 June to 19 June and from 21 June to 4 July, 2012. The two tomato plants were randomly selected with plant diameters ranging from 12 to $16 \mathrm{~mm}$. Two sensors of the Flow $32-1 \mathrm{~K}$ system were installed at a height of $10-20 \mathrm{~cm}$ above the ground surface. According to the standard procedure, in normal (default) mode, the lower flow filter is activated when the heat conveyed by the sap is $\leq 20 \%$ of the power input to the stem from the heater and when the change in temperature is $\leq 0.75^{\circ} \mathrm{C}$. The higher flow filter is activated at a maximum normalized sap velocity of $152 \mathrm{~cm} / \mathrm{h}$. Sap flow data were collected at an interval of $5 \mathrm{~s}$ and the 15 -min average values were recorded by a CR 1000 data logger (Campbell Scientific, Logam, UT, USA). The 
average of two readings was used as the input for the time-variable boundary condition in the HYDRUS-2D model.

Root density length distribution varies with both soil depth and radial distance from the plant. Soil core samples were taken using a root auger with $6-\mathrm{cm}$ diameter around each of three selected tomato plants at the end of the experiment. Soil core samples were taken in four different directions around each tomato plant at soil depths of 0-80 cm with an interval of $10 \mathrm{~cm}$ (Fig. 1), and in total, 120 soil cores were taken for each plant. It should be noted that fewer roots were distributed at the 80-100 cm depth (Machado et al., 2003). The radial distance from the plant was $39 \mathrm{~cm}$ in the east direction (the bed side, almost half of the width of a bed) and $21 \mathrm{~cm}$ (almost half of the distance within a row) in each of the other three directions (i.e., west, north, and south). Soil core samples were washed with fresh water to isolate the roots. Then, root length of the fine roots (diameter $<2 \mathrm{~mm}$; the main roots for water uptake) was measured using a scanner (Regent Instruments Inc., Canada). Root length density of each soil core sample was calculated as the ratio of the total root length in each soil core sample to each core volume.

\subsection{Numerical model}

The HYDRUS-2D model uses numerical methods to solve the Richards' equation for saturated-unsaturated water flow (Šimůnek et al., 2006):

$$
\frac{\partial \theta(h)}{\partial t}=\frac{\partial}{\partial r}\left[K(h) \frac{\partial h}{\partial r}\right]+\frac{\partial}{\partial z}\left[K(h) \frac{\partial h}{\partial z}\right]-\frac{\partial K(h)}{\partial z}-S(r, z, t),
$$

where $\theta$ is the soil water content $\left(\mathrm{cm}^{3} / \mathrm{cm}^{3}\right) ; h$ is the pressure head $(\mathrm{cm}) ; K(h)$ is the unsaturated hydraulic conductivity $(\mathrm{cm} / \mathrm{min}) ; z$ is the vertical coordinate $(\mathrm{cm})$, where upward is assumed to be positive; $r$ is the horizontal coordinate $(\mathrm{cm})$, which is positive for the bed side (east direction) and negative for the furrow side (west direction); $t$ is the time (day); and $S$ is a sink term accounting for root water uptake (unit of per day). The sink term can be calculated as the distribution of the potential transpiration rate $(\mathrm{cm} / \mathrm{d})$ over the root zone using the normalized root length density distribution function $(b(r, z, t)$; unit of per $\mathrm{cm})$ multiplied by the dimensionless water stress response function $(\gamma(h)$ ) (Feddes et al., 1978; Simůnek and Hopmans, 2009; González et al., 2015):

$$
S(r, z, t)=\gamma(h) S_{p}(r, z, t)=\gamma(h) b(r, z, t) L_{t} T_{p},
$$

where $S_{p}(r, z, t)$ is the volume of water removed from a unit volume of soil per unit of time $\left(\mathrm{cm}^{3} /\left(\mathrm{cm}^{3} \cdot \mathrm{d}\right)\right)$, and $L_{t}$ is the surface root length associated with transpiration $(\mathrm{cm})$. In Equation 3, $\gamma(h)$ includes the following parameters: $P_{0}$ is the pressure head value that roots start to extract water from the soil; $P_{\mathrm{Opt}}$ is the pressure head value that roots extract water at the maximum possible rate; $P_{2 \mathrm{H}}$ and $P_{2 \mathrm{~L}}$ are the limiting pressure head values, below which roots no longer extract water at the maximum possible rate (assuming potential transpiration rates of $r_{2 \mathrm{H}}$ and $r_{2 \mathrm{~L}}$, respectively); and $P_{3}$ is the pressure head value that root water uptake stops (usually equal to the wilting point). The following parameter values from the HYDRUS-2D database (Šimůnek et al., 2006) were used in this study: $P_{0}=-10 \mathrm{~cm}, P_{\mathrm{Opt}}=-25 \mathrm{~cm}, P_{2 \mathrm{H}}=-800 \mathrm{~cm}, P_{2 \mathrm{~L}}=-1500 \mathrm{~cm}, P_{3}=$ $-8000 \mathrm{~cm}, r_{2 \mathrm{H}}=0.01 \mathrm{~cm} / \mathrm{d}$, and $r_{2 \mathrm{~L}}=0.1 \mathrm{~cm} / \mathrm{d}$.

\subsubsection{Soil hydraulic properties}

The following equations were used to obtain the parameters of soil water retention curve and unsaturated hydraulic conductivity (Van Genuchten, 1980):

$$
\begin{gathered}
\theta=\theta_{r}+\left(\theta_{s}-\theta_{r}\right)\left[1+(\alpha S)^{n}\right]^{-m} \quad(m=1-1 / n), \\
K(\theta)=K_{s} S_{e}^{l}\left[1-\left(1-S_{e}^{l / m}\right]^{2},\right. \\
S_{e}=\frac{\theta-\theta_{r}}{\theta_{s}-\theta_{r}},
\end{gathered}
$$

where $\theta$ is the soil water content $\left(\mathrm{cm}^{3} / \mathrm{cm}^{3}\right) ; \theta_{s}$ is the saturated soil water content $\left(\mathrm{cm}^{3} / \mathrm{cm}^{3}\right) ; \theta_{r}$ is 
the residual soil water content $\left(\mathrm{cm}^{3} / \mathrm{cm}^{3}\right) ; n, m, \alpha$ and $l$ are empirical shape parameters (dimensionless); $K(\theta)$ is the unsaturated hydraulic conductivity function; $K_{s}$ is the saturated hydraulic conductivity; and $S_{e}$ is the effective water content (dimensionless).

The computer program Retention Curve Program for Unsaturated Soils (Van Genuchten et al., 1998), estimations from the Rosetta neural network model (Schaap, 1999), and observed soil physical properties were used to determine soil hydraulic parameters in the solar greenhouse. Soil hydraulic parameter values used in HYDRUS-2D model are listed in Table 1.

Table 1 Soil hydraulic parameters used in HYDRUS-2D model

\begin{tabular}{ccccccc}
\hline$\theta_{r}\left(\mathrm{~cm}^{3} / \mathrm{cm}^{3}\right)$ & $\theta_{s}\left(\mathrm{~cm}^{3} / \mathrm{cm}^{3}\right)$ & $\alpha$ & $K_{s}(\mathrm{~cm} / \mathrm{d})$ & $n$ & $m>l$ \\
\hline 0.10 & 0.392 & 0.023 & 12.87 & 1.22 & 0.18 & 0.5 \\
\hline
\end{tabular}

\subsubsection{Flow domain, initial and boundary conditions}

Water flow in the root zone in this study was represented by a two-dimensional flow domain with $57.5-\mathrm{cm}$ width (representing half of a $40-\mathrm{cm}$ wide furrow and half of a $75-\mathrm{cm}$ wide bed at the upper boundary) and 90-cm depth (Fig. 2). The flow domain was discretized into 2129 finite nodes and 4469 triangular elements. Fifteen observation points were set in the HYDRUS-2D model, with 5 located in the center of the furrow, 5 at the edge of the furrow, and 5 at the center of the bed (Fig. 2 ). The 5 observation points were set at soil depths of $5,15,35,55$, and $75 \mathrm{~cm}$, respectively.

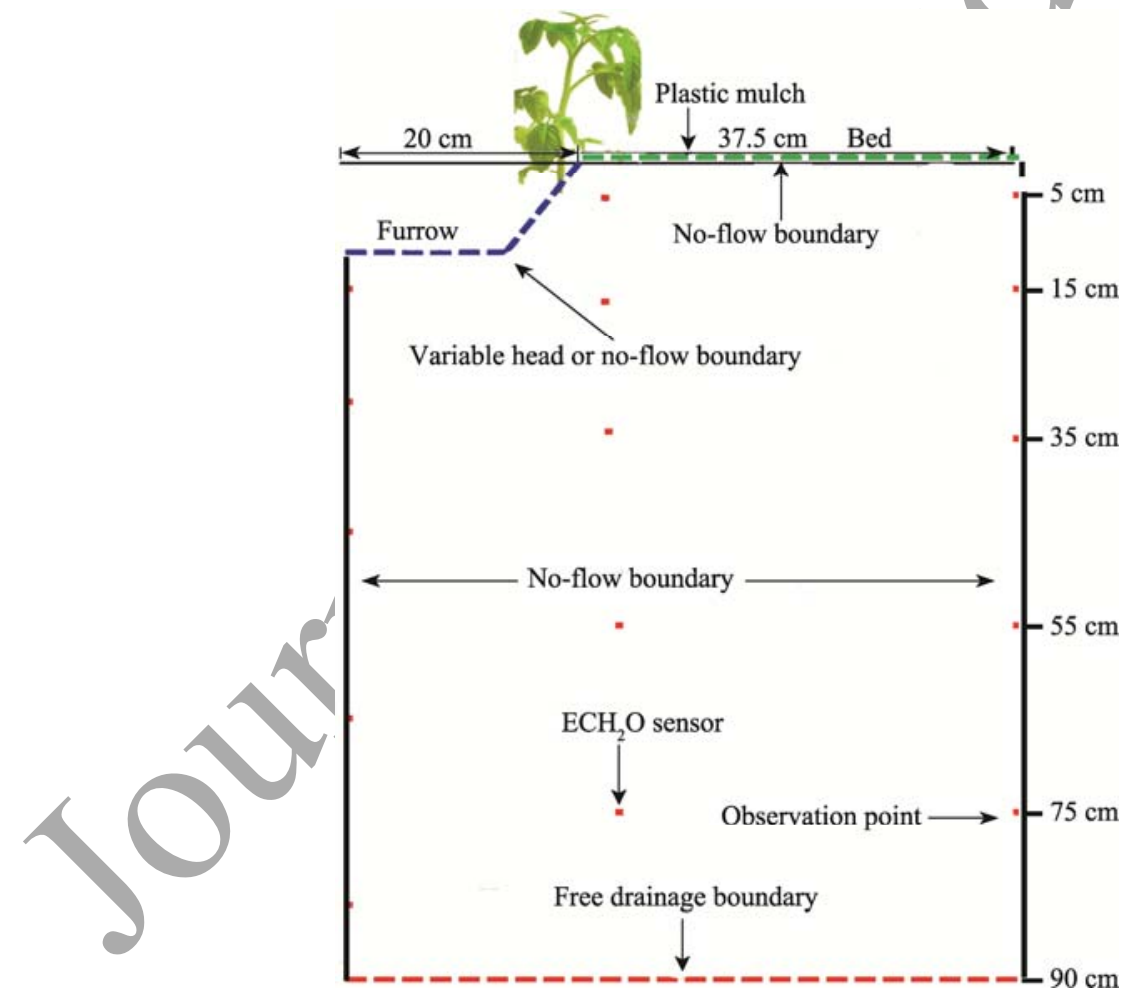

Fig. 2 Schematic of the flow domain and boundary conditions of the flow domain

Soil water contents observed before the simulation started were used as the initial conditions for the flow domain. Boundary conditions of the flow domain that were used to simulate the water flow from the furrow irrigation are shown in Figure 2. By symmetry, no-flow boundary condition was used at the left and right sides of the flow domain. As ground water table in the study area is below $25 \mathrm{~m}$, the effect of groundwater was not considered, and the free drainage boundary condition was used at the bottom of the flow domain $(z=-90 \mathrm{~cm})$. It should be particularly noted that we ignored evaporation from the soil surface because the plastic mulch prevents most of the evaporation and only less than $5.6 \%$ of evapotranspiration is from soil evaporation when plastic 
film is used (Qiu et al., 2015). Thus, the furrow and bed surfaces were set as no-flow boundary conditions when no irrigation events occurred. During irrigation, both sides of the furrow were changed to variable flux boundary conditions.

\subsection{Scenario set-up}

When the initial soil water content (before irrigation) was at a critical level such that tomato plants started to suffer water stress, we irrigated tomato plants with an amount $(I)$ at a given potential transpiration rate $\left(T_{p}\right)$ over a period of time (one irrigation cycle). Soil water content $(\theta)$, potential transpiration rate $\left(T_{p}\right)$, and deep percolation amount $(D)$ in this period (one irrigation cycle) can be simulated by the HYDRUS-2D model. The relationship between irrigation interval $(Q), I$ and $D$ in this period (one irrigation cycle) can be obtained according to the critical level of soil water content (i.e., when tomato plant started to suffer water stress). The same relationship can be used in the next irrigation cycle if the $T_{p}$ is the same.

In this study, the $Q-I-D$ relationship was analyzed for a low $T_{p}$ (a daily average of $1.5 \mathrm{~mm} / \mathrm{d}$, usually during winter and spring), a medium $T_{p}$ (a daily average of $2.7 \mathrm{~mm} / \mathrm{d}$ ) and a high $T_{p}$ (a daily average of $4 \mathrm{~mm} / \mathrm{d}$, usually during summer). There are costs for both irrigation water and irrigation operation. We can adopt a high irrigation frequency with a low amount of water used for each irrigation event when the restriction of water use is the priority. By contrast, when it is important to minimize the cost of irrigation operation, infrequent irrigation with a large amount of water for each irrigation event can be used. However, there may be drainage water for the latter case. Suitable irrigation intervals and irrigation amounts can be obtained according to the $Q-I-D$ relationship determined under different $T_{p}$ values.

\subsection{Data analysis and model performance}

SPSS version 21.0 (IBM Corp., Armonk, NY, USA) was used for linear and non-linear regression analyses of root length density distribution. Surfer software (Golden Software, Inc., Golden, USA) was used to graphically display the observed two-dimensional root length density distribution and soil water content. HYDRUS-2D model provided the simulated two-dimensional root length density graphically. Simulation of soil water dynamics was run from 4 June to 19 June and from 21 June to 4 July, 2012 (30 days) at the fruit bearing and harvesting stages, respectively. It should be pointed out that root length density distribution was relatively stable at these two stages.

Linear correlation with a zero intercept (i.e., $y=b x$ ) between simulated and observed soil water content values was used to assess the accuracy of the model simulations. Model performance was also evaluated using the coefficient of determination $\left(R^{2}\right)$, mean absolute error $(M A E)$, root mean square error $(R M S E)$, mean relative error $(M R E)$, and index of agreement $\left(d_{I A}\right)$ (Willmott, 1981; Willmott and Matsuura, 2005; Martins et al., 2013).

$$
\begin{gathered}
M A E=\frac{1}{N} \sum_{i=1}^{N}\left|O_{i}-S_{i}\right|, \\
R M S E=\left[\frac{\sum_{i=1}^{N}\left(O_{i}-S_{i}\right)^{2}}{N}\right]^{0.5}, \\
M R E=\frac{100}{N} \sum_{i=1}^{N}\left|\frac{O_{i}-S_{i}}{O_{i}}\right|, \\
d_{I A}=1-\frac{\sum_{i=1}^{N}\left(O_{i}-S_{i}\right)^{2}}{\sum_{i=1}^{N}\left(\left|S_{i}-\bar{O}\right|+\left|O_{i}-\bar{O}\right|\right)^{2}},
\end{gathered}
$$

where $S_{i}$ and $O_{i}$ are the simulated and observed values, respectively; $N$ is the number of simulated values; and $\bar{O}$ is the mean observed value. The larger $R^{2}$ and $d_{I A}$ values and the smaller MAE and $R M S E$ values indicate the higher performance of the model. 


\section{Results and discussion}

\subsection{Root length density distribution}

In the solar greenhouse, about $81 \%$ of the total root length density of tomato plants under furrow irrigation was concentrated in the $0-50 \mathrm{~cm}$ soil layers. This value differs from that under drip irrigation, under which roots were mainly concentrated in the top soil layer because of high irrigation frequencies and low irrigation amounts. For example, Zotarelli et al. (2009) found that under drip irrigation, $70 \%-75 \%$ of the total root length density of tomato plants was concentrated in the $0-15 \mathrm{~cm}$ soil layers. Except for irrigation methods, soil texture and soil bulk density may also affect the root length density distribution (Dexter, 2004; Zotarelli et al., 2009). High soil clay content and high soil bulk density exhibit negative effects on root growth, while low soil clay content and low soil bulk density have positive effects on root growth (Oliveira et al., 1996; Dexter, 2004; Zotarelli et al., 2009). In this study, the low soil clay content (12.6\%) and moderate soil bulk density $\left(1.46 \mathrm{~g} / \mathrm{cm}^{3}\right)$ seem to have promoted root growth of tomato plants.

We found an exponential relationship between relative root length density and relative root depth of tomato plants (Eq. 11), being similar to the findings for other plants such as apple trees (Yao, 2004) and grape vines (Zhou, 2007):

$$
L_{r}(Z)=1.2567 \mathrm{e}^{-2.294 Z_{r}} \quad\left(n=8, R^{2}=0.99, P<0.001\right),
$$

where $L_{r}(Z)$ is the relative root length density of tomato plants, which can be obtained from $L_{r}(Z)=L(Z) / L_{\max }$ with $L(Z)$ being the root length density $\left(\mathrm{cm} / \mathrm{cm}^{3}\right)$ and $\mathrm{L}_{\max }$ being the maximum root length density $\left(\mathrm{cm} / \mathrm{cm}^{3}\right.$; average value of $0.2371 \mathrm{~cm} / \mathrm{cm}^{3}$ for the three selected tomato plants); and $Z_{r}$ is the relative root depth, which can be obtained from $Z_{r}=z / z_{m}$ with $z$ being the root depth $(\mathrm{cm})$ and $z_{m}$ being the maximum root depth $(100 \mathrm{~cm})$.

Figure 3 shows the root length density distribution of tomato plants within and between rows under furrow irrigation, with $(0,0)$ being the origin position of each plant. Generally, the root length density distributions of tomato plants are similar when the distances from the origin position are more or less the same. The root length density distributions of tomato plants under furrow irrigation were concentrated horizontally within distances of $0-18 \mathrm{~cm}$ from the origin position to the furrow side, $0-30 \mathrm{~cm}$ from the origin position to the bed side, and $0-18 \mathrm{~cm}$ from the origin position within the same row. The root length density of tomato plants decreased as the horizontal distance from the origin position increased. The range of horizontal distribution of root length density on the bed side was greater than that on the furrow side because of large plant spacing. There were exponential relationships of relative root length density $\left(L_{r}(Z)\right)$ with both relative furrow side distance $\left(R_{F}\right)$ and relative bed side distance $\left(R_{B}\right)$ :

$$
\begin{array}{ll}
L_{r}\left(Z_{F}\right)=0.8923 \mathrm{e}^{-0.771 R_{F}} & \left(n=4, R^{2}=0.84, P<0.10\right), \\
L_{r}\left(Z_{B}\right)=0.7656 \mathrm{e}^{-0.777 R_{B}} & \left(n=7, R^{2}=0.73, P<0.05\right),
\end{array}
$$

where $R_{F}$ is the relative furrow side distance, which can be obtained from $R_{F}=r_{F} / r_{F m}$, with $r_{F}$ being the distance from the origin position of tomato plant to the furrow side (cm) and $r_{F m}$ being the maximum distance from the origin position of tomato plant to the furrow side $(21 \mathrm{~cm})$; and $R_{B}$ is the relative bed side distance, which can be obtained from $R_{B}=r_{B} / r_{B m}$, with $r_{B}$ being the distance from the origin position of tomato plant to the bed side $(\mathrm{cm})$ and $r_{B m}$ being the maximum distance from the origin position of tomato plant to the bed side $(39 \mathrm{~cm})$.

Figure 3 also clearly shows an approximate axial symmetry in the horizontal distribution of root length density with respect to distance from the origin position. The average root length density at the same sampling depth and radial distance within the root zone of the three selected tomato plants was used for simulating the two-dimensional depth and radial distribution. As described above, there are exponential relationships between relative root length density and distance from the origin position in the both vertical and horizontal directions. Thus, the two-dimensional root length density of tomato plants used in the HYDRUS-2D model (Vrugt et al., 2001a; Šimůnek et al., 2006) could be estimated as follows: 


$$
\beta(r, z)=\left(1-z / z_{m}\right)\left(1-r_{B} / r_{B m}\right) \exp ^{-\left(\frac{p_{z}}{z_{m}}\left|Z^{*}-z\right|+\frac{p_{r}}{r_{B m}}\left|R^{*}-r_{B}\right|\right)},
$$

where $\beta(r, z)$ is the dimensionless two-dimensional spatial distribution of root water uptake; and $p_{z}$, $p_{r}, Z^{*}$ and $R^{*}$ are the empirical coefficients, which can represent the asymmetrical root water uptake with radius and depth to allow for the maximum root water uptake at any depth (Vrugt et al., 2001a; Zhou et al., 2007). The empirical coefficients of $Z^{*}$ and $R^{*}$ shown in Table 2 indicate that the maximum root length density was at a depth of $10 \mathrm{~cm}$ and at the origin of the plant, being consistent with the observed values (Fig. 4a). The simulated two-dimensional root length density used in the HYDRUS-2D model is shown in Figure 4b. There was a significant relationship between observed and simulated two-dimensional root length density values $\left(R^{2}=0.57, P<0.001\right)$.

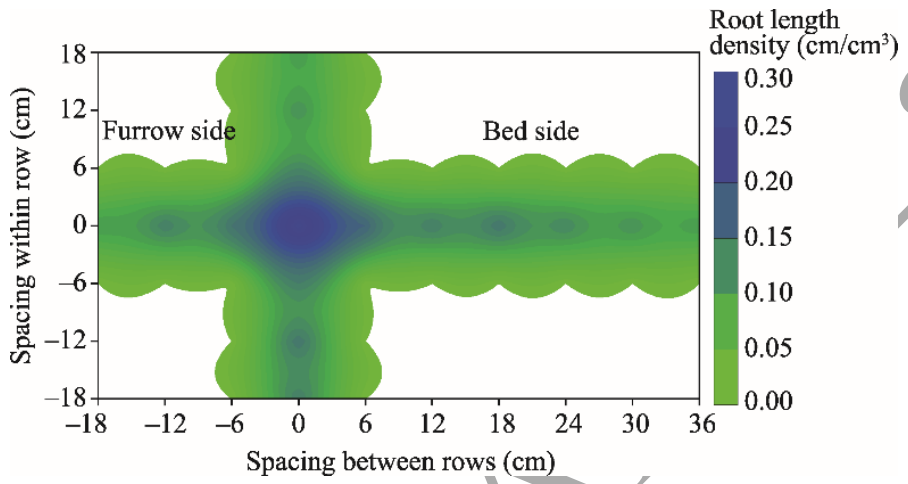

Fig. 3 Horizontal distribution of root length density of tomato plants under furrow irrigation based on soil sampling

Table 2 Parameter values of two-dimensional root length density used in the root water uptake function

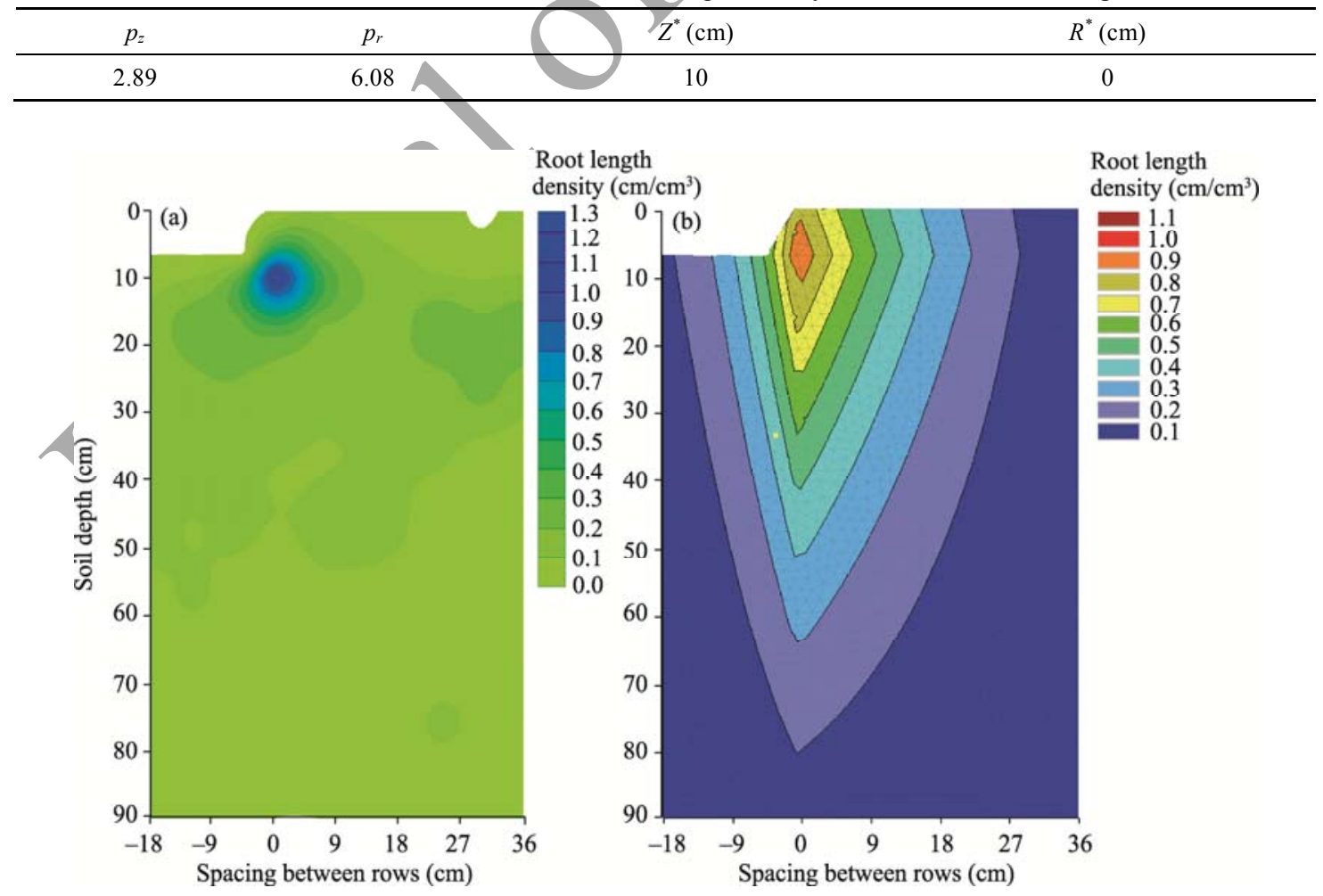

Fig. 4 Observed (a) and simulated (b) two-dimensional root length density values of tomato plants 


\subsection{Soil water distribution}

Overall, differences of soil water content at different positions in the upper soil layers $(0-40 \mathrm{~cm})$ were larger than those in the deeper soil layers $(40-80 \mathrm{~cm})$. This may be due to that the upper soil layers are more directly affected by evapotranspiration and irrigation. After each irrigation event, soil water content increased rapidly in the upper soil layers $(0-40 \mathrm{~cm})$, especially in the top layer $(0-20 \mathrm{~cm})$, and the increases mainly occurred in the center and at the edge of the furrow (Fig. 5). The difference of soil water content between the edge of the furrow and the center of the bed in the $40-80 \mathrm{~cm}$ soil layers was negligibly small because the strictly controlled irrigation limited water infiltration to a particular soil depth.
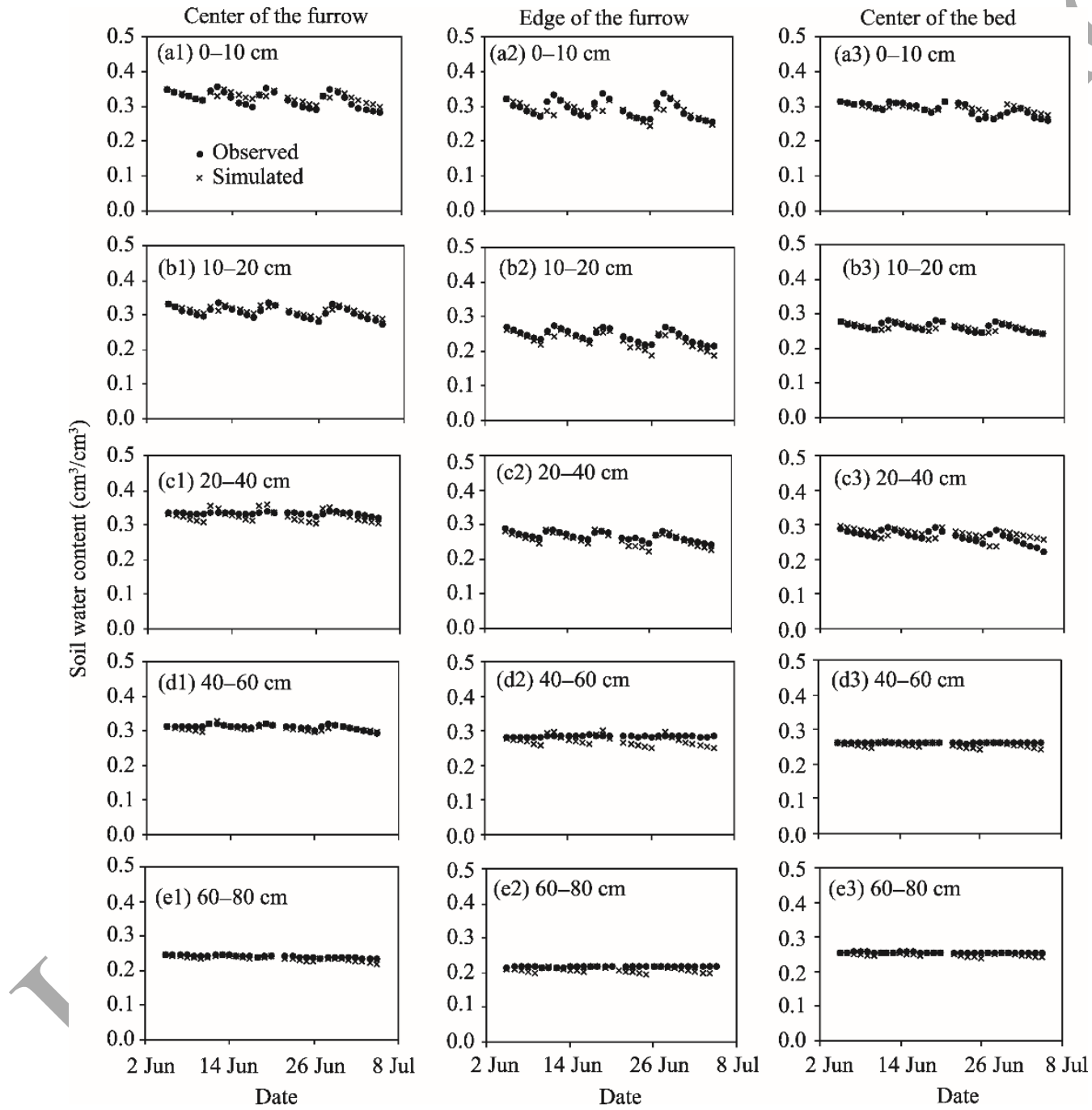

Fig. 5 Comparison of observed and simulated soil water content values at different locations (i.e., center of the furrow, edge of the furrow and center of the bed) and different soil depths

In this study, we used the HYDRUS-2D model to simulate soil water content at different locations and depths. Soil water content values simulated by the HYDRUS-2D model were compared with those observed by the $\mathrm{ECH}_{2} \mathrm{O}$ sensors (Fig. 5). It can be seen that the simulated values generally agreed well with the observed values both spatially and temporally, except for some values at deeper soil layers, e.g., $40-60 \mathrm{~cm}$ soil layer at the edge of the furrow. The simulation errors were small, with $R M S E$ ranging from 0.006 to $0.020 \mathrm{~cm}^{3} / \mathrm{cm}^{3}, M A E$ varying from 0.005 to $0.018 \mathrm{~cm}^{3} / \mathrm{cm}^{3}$, and $M R E$ less than $7 \%$ (Table 3). It should be noted that the errors 
Table 3 Simulation error analyses of soil water content at different locations (i.e., center of the furrow, edge of the furrow and center of the bed) and different soil depths

\begin{tabular}{|c|c|c|c|c|}
\hline \multirow{2}{*}{ Soil depth (cm) } & \multirow{2}{*}{ Error parameter } & \multicolumn{3}{|c|}{ Location } \\
\hline & & Center of the furrow & Edge of the furrow & Center of the bed \\
\hline \multirow[t]{3}{*}{$0-10$} & $R M S E\left(\mathrm{~cm}^{3} / \mathrm{cm}^{3}\right)$ & 0.014 & 0.019 & 0.011 \\
\hline & $M A E\left(\mathrm{~cm}^{3} / \mathrm{cm}^{3}\right)$ & 0.012 & 0.013 & 0.008 \\
\hline & $\operatorname{MRE}(\%)$ & 3.7 & 4.2 & 2.8 \\
\hline \multirow[t]{3}{*}{$10-20$} & $\operatorname{RMSE}\left(\mathrm{cm}^{3} / \mathrm{cm}^{3}\right)$ & 0.009 & 0.014 & 0.010 \\
\hline & $\operatorname{MAE}\left(\mathrm{cm}^{3} / \mathrm{cm}^{3}\right)$ & 0.008 & 0.011 & 0.007 \\
\hline & $M R E(\%)$ & 2.7 & 4.8 & 2. \\
\hline \multirow[t]{3}{*}{$20-40$} & $\operatorname{RMSE}\left(\mathrm{cm}^{3} / \mathrm{cm}^{3}\right)$ & 0.015 & 0.011 & \\
\hline & $M A E\left(\mathrm{~cm}^{3} / \mathrm{cm}^{3}\right)$ & 0.013 & 0.009 & 0 . \\
\hline & $M R E(\%)$ & 4.0 & 3.6 & \\
\hline \multirow[t]{3}{*}{$40-60$} & $R M S E\left(\mathrm{~cm}^{3} / \mathrm{cm}^{3}\right)$ & 0.007 & 0.018 & 0.010 \\
\hline & $\operatorname{MAE}\left(\mathrm{cm}^{3} / \mathrm{cm}^{3}\right)$ & 0.005 & 0.016 & 0.007 \\
\hline & $M R E(\%)$ & 1.6 & 5.6 & 2.8 \\
\hline \multirow[t]{3}{*}{$60-80$} & $R M S E\left(\mathrm{~cm}^{3} / \mathrm{cm}^{3}\right)$ & 0.006 & 0.0 & 0.007 \\
\hline & $\operatorname{MAE}\left(\mathrm{cm}^{3} / \mathrm{cm}^{3}\right)$ & 0.005 & & 0.005 \\
\hline & $M R E(\%)$ & 2.2 & 4.2 & 2.0 \\
\hline
\end{tabular}

Note: $R M S E$, root mean square error; $M A E$, mean absolute error; $M R E$, mean relative error.

were slightly larger at the edge of the furrow and in the $20-40 \mathrm{~cm}$ soil layer in the bed. The differences between observed and simulated values may be attributed to the following reasons. Root length density distribution influences root water uptake and in turn affects soil water content. The accuracy of estimation of root length density also has a direct effect on the simulation of soil water content (Zhou et al., 2007). In this study, the differences between observed and estimated root length density distributions (see Fig. 4) may lead to a subsequent exaggeration of the differences between observed and estimated values in root water uptake, and the exaggerated differences in turn affect the simulation of soil water content in the deeper soil layers. Root water uptake depends not only on the root length density distribution but also on soil water availability (Vrugt et al., 2001b). Strictly controlled irrigation limited the available water and water infiltration to deeper soil layers especially at the edge of the furrow and the center of the bed and thus affected root water uptake and soil water content in the deeper soil layers.

Table 4 shows the statistical indicators of goodness of fit for the HYDRUS-2D model at different locations, i.e., center of the furrow, edge of the furrow and center of the bed. Regression coefficient $(b)$ and coefficient of determination $\left(R^{2}\right)$ ranged from 0.967 to 0.997 and 0.58 to 0.91 $(P<0.001)$ at the three locations, respectively, indicating that most of the total variance of the observed values could be explained by the HYDRUS-2D model. Simulation errors were all small at each one of locations, with RMSE of $0.011-0.015 \mathrm{~cm}^{3} / \mathrm{cm}^{3}, M A E$ of $0.009-0.012 \mathrm{~cm}^{3} / \mathrm{cm}^{3}$, and $M R E$ of $2.8 \%-4.5 \%$. Values of $d_{I A}$ ranged from 0.88 to 0.98 , indicating that the mean square error is close to the potential error. Based on these results, we conclude that soil water contents simulated by the HYDRUS-2D model fitted well with those observed by the $\mathrm{ECH}_{2} \mathrm{O}$ sensors. Therefore, the HYDRUS-2D model is suitable for simulating soil water distribution in a furrow irrigation system. Furthermore, the performance of the HYDRUS-2D model in our study was slightly better than that in other studies (Crevoisier et al., 2008; Ebrahimian et al., 2012). For instance, Ebrahimian et al. (2012) used a HYDRUS-2D model to simulate soil water content and the result showed that the $R^{2}$ values for both fixed and variable alternate furrow irrigation treatments and for conventional furrow irrigation treatments were in the range of 0.571 to 0.878 with standard errors ranging from 0.089 to $0.096 \mathrm{~cm}^{3} / \mathrm{cm}^{3}$. The better performance of the HYDRUS-2D model in our study may be due to a full consideration of root water uptake in the model.

The observed and simulated two-dimensional soil water contents during an irrigation event are shown in Figure 6. Soil water content values simulated by the HYDRUS-2D model well matched 
Table 4 Statistical indicators of goodness of fit for the HYDRUS-2D model at different locations (i.e., center of the furrow, edge of the furrow and center of the bed)

\begin{tabular}{ccccccc}
\hline Location & $b$ & $R^{2}$ & $R M S E\left(\mathrm{~cm}^{3} / \mathrm{cm}^{3}\right)$ & $M A E\left(\mathrm{~cm}^{3} / \mathrm{cm}^{3}\right)$ & $M R E(\%)$ & $d_{I A}$ \\
\hline Center of the furrow & 0.997 & 0.91 & 0.011 & 0.009 & 0.012 & 2.8 \\
Edge of the furrow & 0.967 & 0.86 & 0.015 & 0.009 & 4.5 & 0.94 \\
Center of the bed & 0.996 & 0.58 & 0.012 & 0.010 & 3.4 & 0.88 \\
Average & 0.988 & 0.89 & 0.013 & 0.97 \\
\hline
\end{tabular}

Note: $b$, regression coefficient; $R^{2}$, coefficient of determination; $R M S E$, root mean square error; $M A E$, mean absolute error; $M R E$, mean relative error; $d_{I A}$, index of agreement.

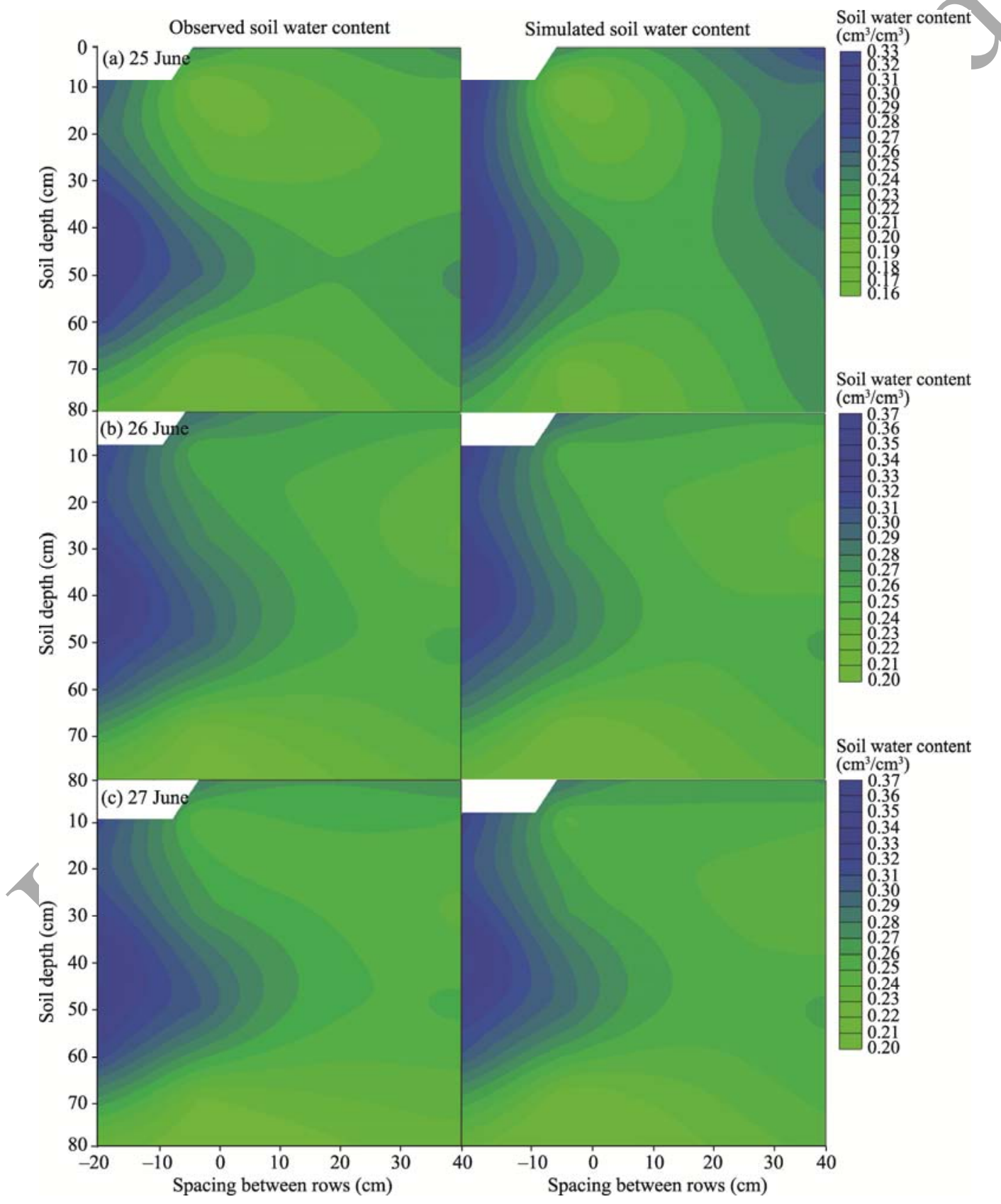

Fig. 6 Comparison of observed (left column) and simulated (right column) two-dimensional soil water content values on (a) 25 June (before irrigation), (b) 26 June (during the day of irrigation), and (c) 27 June (after irrigation) 
with those observed by the $\mathrm{ECH}_{2} \mathrm{O}$ sensors before irrigation, during the day of irrigation, and after irrigation. The values of $b, R^{2}, R M S E, M A E$ and $d_{I A}$ ranged from 0.960 to $1.015,0.74$ to 0.85 , 0.016 to $0.020 \mathrm{~cm}^{3} / \mathrm{cm}^{3}, 0.012$ to $0.018 \mathrm{~cm}^{3} / \mathrm{cm}^{3}$ and 0.994 to 0.997 , respectively (Table 5).

Table 5 Statistical indicators of goodness of fit for the HYDRUS-2D model during an irrigation event (i.e., before irrigation, during the day of irrigation, and after irrigation)

\begin{tabular}{cccccc}
\hline Date & $b$ & $R^{2}$ & $R M S E\left(\mathrm{~cm}^{3} / \mathrm{cm}^{3}\right)$ & $M A E\left(\mathrm{~cm}^{3} / \mathrm{cm}^{3}\right)$ & $d_{I A}$ \\
\hline 25 June (before irrigation) & 0.960 & 0.77 & 0.020 & 0.016 & 0.994 \\
26 June (during the day of irrigation) & 1.015 & 0.85 & 0.016 & 0.018 & 0.997 \\
27 June (after irrigation) & 1.008 & 0.74 & 0.020 & 0.012 & 0.996 \\
\hline
\end{tabular}

Note: $b$, regression coefficient; $R^{2}$, coefficient of determination; RMSE, root mean square error; $M A E$, mean absolute error; $d_{I A}$, index of agreement.

\subsection{Scenario analysis}

Relationships of irrigation amount $(I)$ with irrigation interval $(Q)$ and deep percolation amount $(D)$ under different daily average potential transpiration rate $\left(T_{p}\right)$ values for no water-stress cases are shown in Figure 7. The trends of the $Q-I-D$ relationship were as follows: (1) at the same value of $I$, $Q$ with a low daily average $T_{p}$ was higher than $Q$ with a high daily average $T_{p} ;(2)$ at the same value of $Q$, both $I$ and $D$ with a low daily average $T_{p}$ were lower than $I$ and $D$ with a high daily average $T_{p} ;$ (3) under daily average $T_{p}$ values of $1.5,2.7$ and $4.0 \mathrm{~mm} / \mathrm{d}$, $D$ began to appear when $I$ was greater than 28, 31 and $34 \mathrm{~mm}$, respectively, and the corresponding $Q$ values were 17, 9 and 6 days. $Q$ increased rapidly as $I$ increased up to $60 \mathrm{~mm}$, afterwards there was only a small increase in $Q$ when $I$ was greater than $60 \mathrm{~mm}$. This indicates that most of the increase in $I$ became an increase in $D$. Under daily average $T_{p}$ values of $1.5,2.7$ and $4.0 \mathrm{~mm} / \mathrm{d}, Q$ values were 25,13 and 8 days, respectively when $I$ was $60 \mathrm{~mm}$. However, under the same daily average values of $T_{p}$, the maximum $Q$ values were 29, 17 and 11 days, respectively.
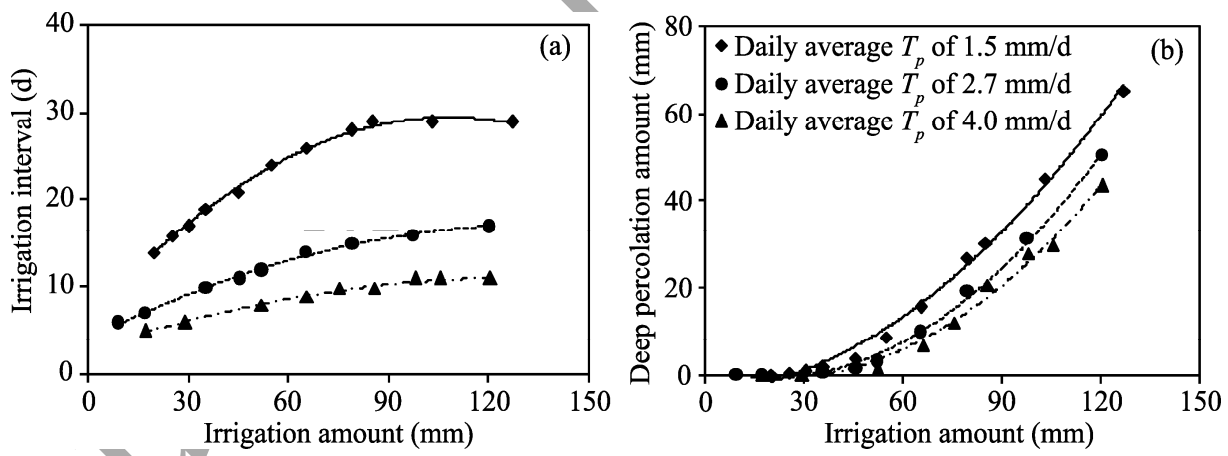

Fig. 7 Relationships (a) between irrigation amount and irrigation interval and (b) between irrigation amount and deep percolation amount under different daily average potential transpiration rate $\left(T_{p}\right)$ values

When the priority was to limit water use, the maximum $I$ values were no more than 28 and 34 $\mathrm{mm}$ and the corresponding $Q$ values were less than 17 and 6 days for lower daily average $T_{p}(1.5$ $\mathrm{mm} / \mathrm{d})$ and higher daily average $T_{p}(4.0 \mathrm{~mm} / \mathrm{d})$, respectively. When the priority was to limit the irrigation frequency, $I$ was $60 \mathrm{~mm}$ and the corresponding $Q$ values were no more than 25 and 13 days for lower daily average $T_{p}(1.5 \mathrm{~mm} / \mathrm{d})$ and higher daily average $T_{p}(4.0 \mathrm{~mm} / \mathrm{d})$, respectively. Furthermore, the corresponding $D$ values were $10 \%-18 \%$ of $I$.

The result of high irrigation frequency with a low amount of water for each irrigation event in this study was close to that in our previous study (Qiu, 2014). Actually, infrequent irrigation with a large amount of water for each irrigation event approximates the practice of local farmers. However, this irrigation method results in $10 \%-18 \%$ of the irrigation water loss. Therefore, infrequent irrigation with a large amount of water for each irrigation event is not recommended for arid regions. 


\section{Conclusions}

In this study, the HYDRUS-2D model was calibrated to simulate soil water dynamics with consideration of root water uptake for furrow irrigated tomato plants in a solar greenhouse. The simulated soil water contents at different locations (i.e., center of the furrow, edge of the furrow and center of the bed) agreed well with the observed soil water contents. The results suggest that the HYDRUS-2D model with consideration of root water uptake can be used to simulate the dynamics of soil water movement for furrow irrigated tomato plants in greenhouses. The HYDRUS-2D model with calibrated parameters can also provide valuable information for the avoidance of water stress so that furrow irrigation can be optimally scheduled for tomato production in greenhouses in arid areas. To sum up, high irrigation frequency with a low amount of water for each irrigation event is recommended for arid regions.

\section{Acknowledgements}

This study was supported by the National Key Research and Development Program of China (2016YFC0400207), the National Natural Science Foundation of China $(51222905,51621061,51509130)$, the Natural Science Foundation of Jiangsu Province, China (BK20150908), the Discipline Innovative Engineering Plan (111 Program, B14002) and the Jiangsu Key Laboratory of Agricultural Meteorology Foundation (JKLAM1601).

\section{References}

Abbasi F, Feyen J, Van Genuchten M T. 2004. Two-dimensional simulation of water flow and solute transport below furrows: model calibration and validation. Journal of Hydrology, 290(1-2): 63-79.

Crevoisier D, Popova Z, Mailhol J C, et al. 2008. Assessment and simulation of water and nitrogen transfer under furrow irrigation. Agricultural Water Management, 95(4): 354-366.

Dexter A R. 2004. Soil physical quality: part I. Theory, effects of soil texture, density, and organic matter, and effects on root growth. Geoderma, 120(3-4): 201-214.

Ebrahimian H, Liaghat A, Parsinejad M, et al. 2012. Comparison of one- and two-dimensional models to simulate alternate and conventional furrow fertigation. Journal of Irrigation and Drainage Engineering, 138(10): 929-938.

Feddes R A, Kowalik P J, Zaradny H. 1978. Simulation of Field Water Use and Crop Yield. New York: John Wiley and Sons, 189.

González M G, Ramos T B, Carlesso R, et al, 2015. Modelling soil water dynamics of full and deficit drip irrigated maize cultivated under a rain shelter. Biosystems Engineering, 132: 1-18.

Harmanto, Salokhe V M, Babel M S, et al. 2005. Water requirement of drip irrigated tomatoes grown in greenhouse in tropical environment. Agricultural Water Management, 71(3): 225-242.

He H B, Yang R, Wu L Q, et al. 2016. The growth characteristics and yield potential of rice (Oryza sativa) under non-flooded irrigation in arid region. Annals of Applied Biology, 168(3): 337-356.

Iqbal S, Guber A K, Khan H Z. 2016. Estimating nitrogen leaching losses after compost application in furrow irrigated soils of Pakistan using HYDRUS-2D software. Agricultural Water Management, 168: 85-95.

Machado R M, Do Rosário M, Oliveira G, et al. 2003. Tomato root distribution, yield and fruit quality under subsurface drip irrigation. Plant and Soil, 255(1): 333-341.

Mailhol J, Ruelle P, Nemeth I. 2001. Impact of fertilisation practices on nitrogen leaching under irrigation. Irrigation Science, 20(3): 139-147.

Martins J D, Rodrigues G C, Paredes P, et al. 2013. Dual crop coefficients for maize in southern Brazil: model testing for sprinkler and drip irrigation and mulched soil. Biosystems Engineering, 115(3): 291-310.

Ning S R, Shi J C, Zuo Q, et al. 2015. Generalization of the root length density distribution of cotton under film mulched drip irrigation. Field Crops Research, 177: 125-136.

Oliveira M D R G, Calado A M, Portas C A M. 1996. Tomato root distribution under drip irrigation. Journal of the American Society for Horticultural Science, 121(4): 644-648.

Qiu R J, Kang S Z, Li F S, et al. 2011. Energy partitioning and evapotranspiration of hot pepper grown in greenhouse with furrow and drip irrigation methods. Scientia Horticulturae, 129(4): 790-797.

Qiu R J, Song J J, Du T S, et al. 2013. Response of evapotranspiration and yield to planting density of solar greenhouse grown tomato in Northwest China. Agricultural Water Management, 130: 44-51. 
Qiu R J. 2014. Water and heat dynamics and simulation in soil-plant system in greenhouse. PhD Dissertation. Beijing: China Agricultural University. (in Chinese)

Qiu R J, Du T S, Chen R Q. 2015. Application of the dual crop coefficient model for estimating tomato evapotranspiration in greenhouse. Journal of Hydraulic Engineering, 46(6): 678-686. (in Chinese)

Schaap M G. 1999. Rosetta lite version 1.0. Predicting soil hydraulic parameters from basic data. In: U.S. Salinity Laboratory, USDA/ARS. Riverside, CA.

Šimůnek J, Van Genuchten M T, Šejna M. 2006. User manual, version 1.0. The HYDRUS software package for simulating the two-and three-dimensional movement of water, heat, and multiple solutes in variably-saturated media. In: PC Progress, Prague, Czech Republic.

Šimůnek J, Hopmans J W. 2009. Modeling compensated root water and nutrient uptake. Ecological Modelling, 220(4): 505-521.

Tafteh A, Sepaskhah A R. 2012. Application of HYDRUS-1D model for simulating water and nitrate leaching from continuous and alternate furrow irrigated rapeseed and maize fields. Agricultural Water Management, 113: 19-29.

Van Genuchten M T. 1980. A close-form equation for predicting the hydraulic conductivity of unsaturated soils, Soil Science Society of America Journal, 44(5): 892-898.

Van Genuchten M T, Šimůnek J, Leij F J, et al. 1998. RETC, version 6.0, code for quantifying the hydraulic functions of unsaturated soils. In: USDA-ARS, US Salinity Lab. Riverside, CA.

Vrugt J A, Hopmans J W, Šimunek J. 2001a. Calibration of a two-dimensional root water uptake model. Soil Science Society of America Journal, 65(4): 1027-1037.

Vrugt J A, Van Wijk M T, Hopmans J W, et al. 2001b. One-, two-, and three-dimensional root water uptake functions for transient modeling. Water Resources Research, 37(10): 2457-2470.

Wang Z Y, Liu Z X, Zhang Z K, et al. 2009. Subsurface drip irrigation scheduling for cucumber (Cucumis sativus L.) grown in solar greenhouse based on $20 \mathrm{~cm}$ standard pan evaporation in Northeast China. Scientia Horticulturae, 123(1): 51-57.

Willmott C J. 1981. On the validation of models. Physical Geography, 2(2): 184-194.

Willmott C J, Matsuura K. 2005. Advantages of the mean absolute error (MAE) over the root mean square error (RMSE) in assessing average model performance. Climate Research, 30(1): 79-82.

Yao L M. 2004. Study on root water uptake model of apple tree. MSc Thesis. Yangling: Northwest A\&F University. (in Chinese)

Yuan B Z, Sun J, Nishiyama S. 2004. Effect of drip irrigation on strawberry growth and yield inside a plastic greenhouse. Biosystems Engineering, 87(2): 237-245.

Zhang J X, Zhang X M, Shan Y Y, et al. 2014. Numerical simulation on soil water infiltration for spring wheat under ridge furrow irrigation. Journal of Arid Land Resources and Environment, 28(6): 165-170. (in Chinese)

Zhang Y Y, Wu P T, Zhao X N, et al. 2013. Simulation of soil water dynamics for uncropped ridges and furrows under irrigation conditions. Canadian Journal of Soil Science, 93(1): 85-98.

Zhou Q Y. 2007. Experiment and simulation for soil water dynamics under alternate partial root-zone drip irrigation in vinery. PhD Dissertation. Beijing: China Agricultural University. (in Chinese)

Zhou Q Y, Kang S Z, Zhang L, et al. 2007. Comparison of APRI and Hydrus-2D models to simulate soil water dynamics in a vineyard under alternate partial root zone drip irrigation. Plant and Soil, 291(1-2): 211-223.

Zotarelli L, Scholberg J M, Dukes M D, et al. 2009. Tomato yield, biomass accumulation, root distribution and irrigation water use efficiency on a sandy soil, as affected by nitrogen rate and irrigation scheduling. Agricultural Water Management, 96(1): 23-34.

Zuo Q, Shi J C, Li Y L, et al. 2006. Root length density and water uptake distributions of winter wheat under sub-irrigation. Plant and Soil, 285(1-2): 45-55. 